\title{
Investigating Carbazole Jacketed Precursor Dendrimers: Sonochemical Synthesis, Characterization, and Electrochemical Crosslinking Properties
}

Prasad Taranekar, Timothy Fulghum, Derek Patton, Ramakrishna Ponnapati, Gabriel

Clyde, and Rigoberto Advincula*

Department of Chemistry, University of Houston, Houston TX 77024.

radvincula@uh.edu

Table of Contents

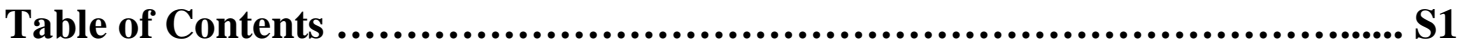

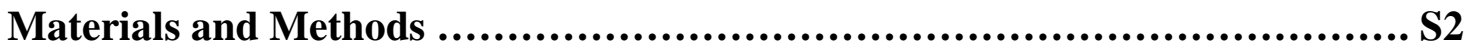

MALDI and TGA of dendrimers... ......................................... S3

AFM Profilometry studies..................................................... S4

Scan Rate studies.................................................................S5

AFM Morphological studies..................................................S6

Cyclic Voltammogram Studies..................................................S8

Band Gap Studies............................................................. S9

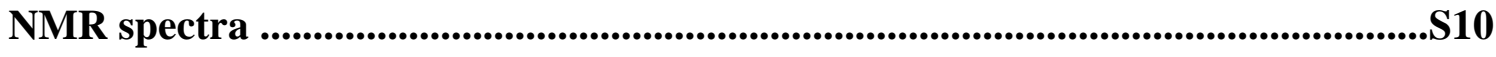




\section{Materials and Methods.}

Solvents were properly distilled and collected immediately prior to use. Other reagents and chemicals were commercially available. Analytical grade chemicals were purchased from Aldrich Chemical Company and were used without further purification.

NMR spectra were recorded using General Electric QE 300 spectrometer $\left({ }^{1} \mathrm{H}\right.$ 300MHz). UV-Vis spectra were recorded using Agilent 8453 Spectrometer. Fluorescence spectra were obtained on Perkin-Elmer LS-45 luminescence spectrometer. The size

exclusion chromatography (SEC) analysis was performed using a Viscotek 270 quad detector equipped with VE3210 UV/VIS detector and VE3580 RI detector. The columns used for finding the SEC number average molecular weight $\left(\mathrm{M}_{\mathrm{n}} \mathrm{sec}\right)$ were of the G3000HHR and GHMHR-M viscogel type. Matrix Assisted Laser Dessorption Ionization- time of flight (MALDI-TOF) analysis was performed on a Voyager DE-STR system from Applied Biosystems. A high voltage of $20 \mathrm{KV}$, pulse rate of $20 \mathrm{~Hz}$ and $\mathrm{N}_{2}$ Laser $(337 \mathrm{~nm})$ was used to probe the sample mass. Cyclic Voltammetry was performed on an Amel 2049 potentiostat and power lab/4SP system with a three-electrode cell. In all the measurements the counter electrode was platinum wire and Indium Tin Oxide (ITO) or gold coated glass was used as working electrode. The ITO was pretreated with the RCA recipe $\left(\mathrm{H}_{2} \mathrm{O} / \mathrm{H}_{2} \mathrm{O}_{2} / \mathrm{NH}_{3}: 15.1 \mathrm{~g} / 26.6 \mathrm{~g} / 8.57 \mathrm{~g}\right)$. Gold electrodes were cleaned with a plasma ion cleaner (Plasmod, March). The QCM apparatus, probe, and crystals are available from MAXTEK Inc. The data acquisition was done using an RQCM (Research Quartz Crystal Microbalance, MAXTEK, Inc.) system equipped with an inbuilt phase lock oscillator, and the RQCM Data-Log Software. This was coupled with the Amel potentiostat to generate EC-QCM results. A $5 \mathrm{MHz}$ AT-cut Au-coated quartz crystal with 
an effective area of $1.327 \mathrm{~cm}^{2}$ was used as a working electrode. Platinum as a counter electrode and $\mathrm{Ag} / \mathrm{AgCl}$ as a reference was used to measure the in-situ polymer adsorption changes during cyclic voltammetry. To initiate the experiment, an inert probe was first immersed in methylene chloride until a stable frequency was obtained. Tapping mode (270-410 kHz, Si tip) Atomic Force Microscopy (AFM) using a PicoPlus (Molecular Imaging) system was used to analyze the height profile of the dendrimers with high image resolution. All AFM images shown herein are processed using SPIP software (Scanning Probe Image Processor, version: 4.0.6.0 Imagemet.com) to flatten and filter.

\section{MALDI and TGA of dendrimers.}
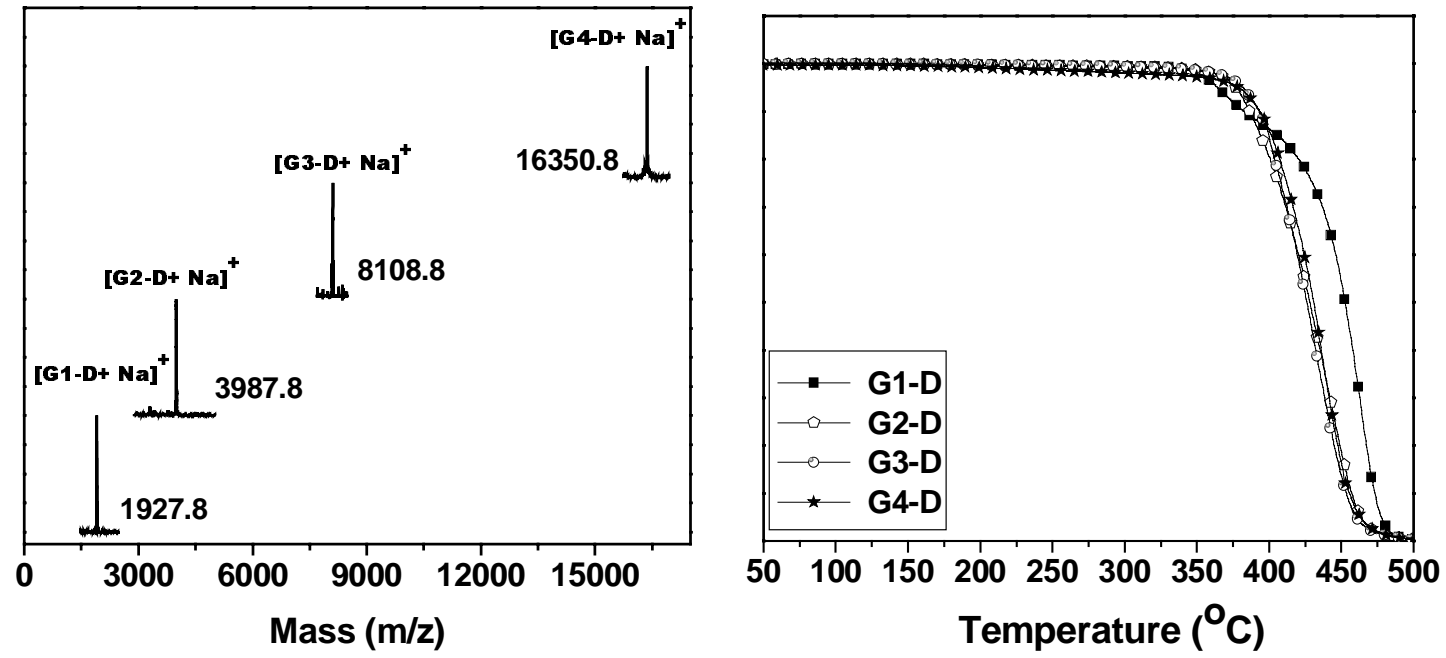

Figure 1. (a) MALDI-TOF (b) TGA curves. 
3. AFM Profilometry studies. For thickness measurement of the cross-linked films

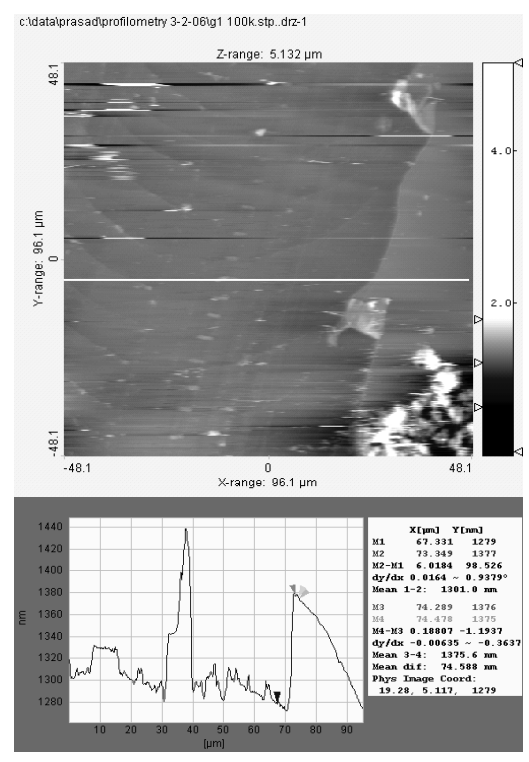

(a)

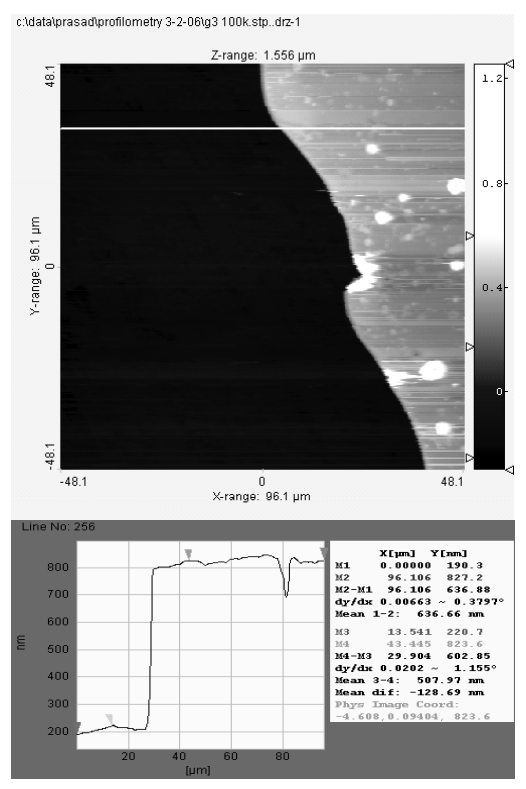

(c)

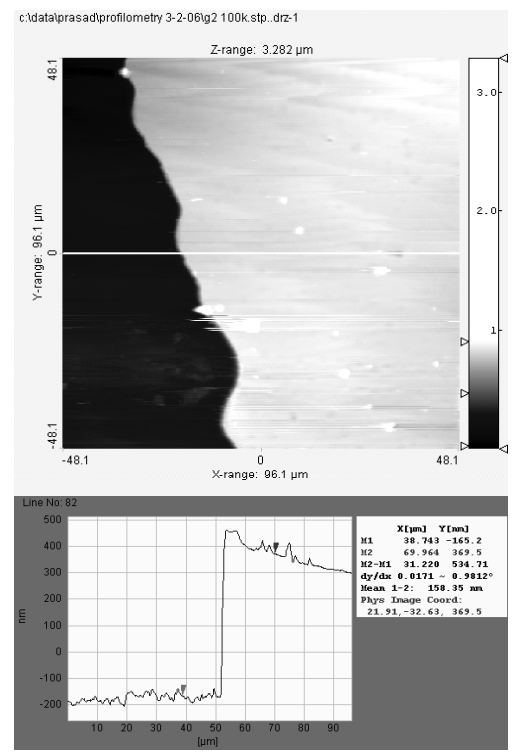

(b)

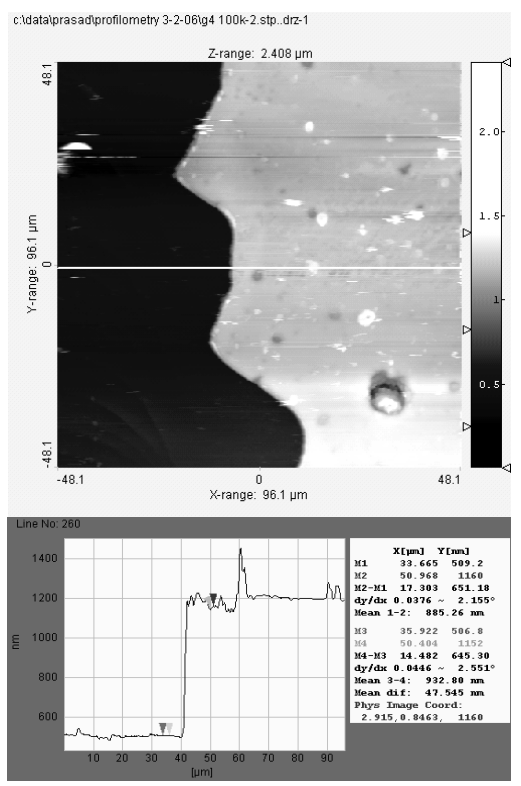

(d)

Figure 2. AFM profilometery of the cross-linked films: (a) G1-D-clk (b) G2-D-clk (c) G3-D-clk (d) G4-D-clk. 


\section{Scan Rate studies.}
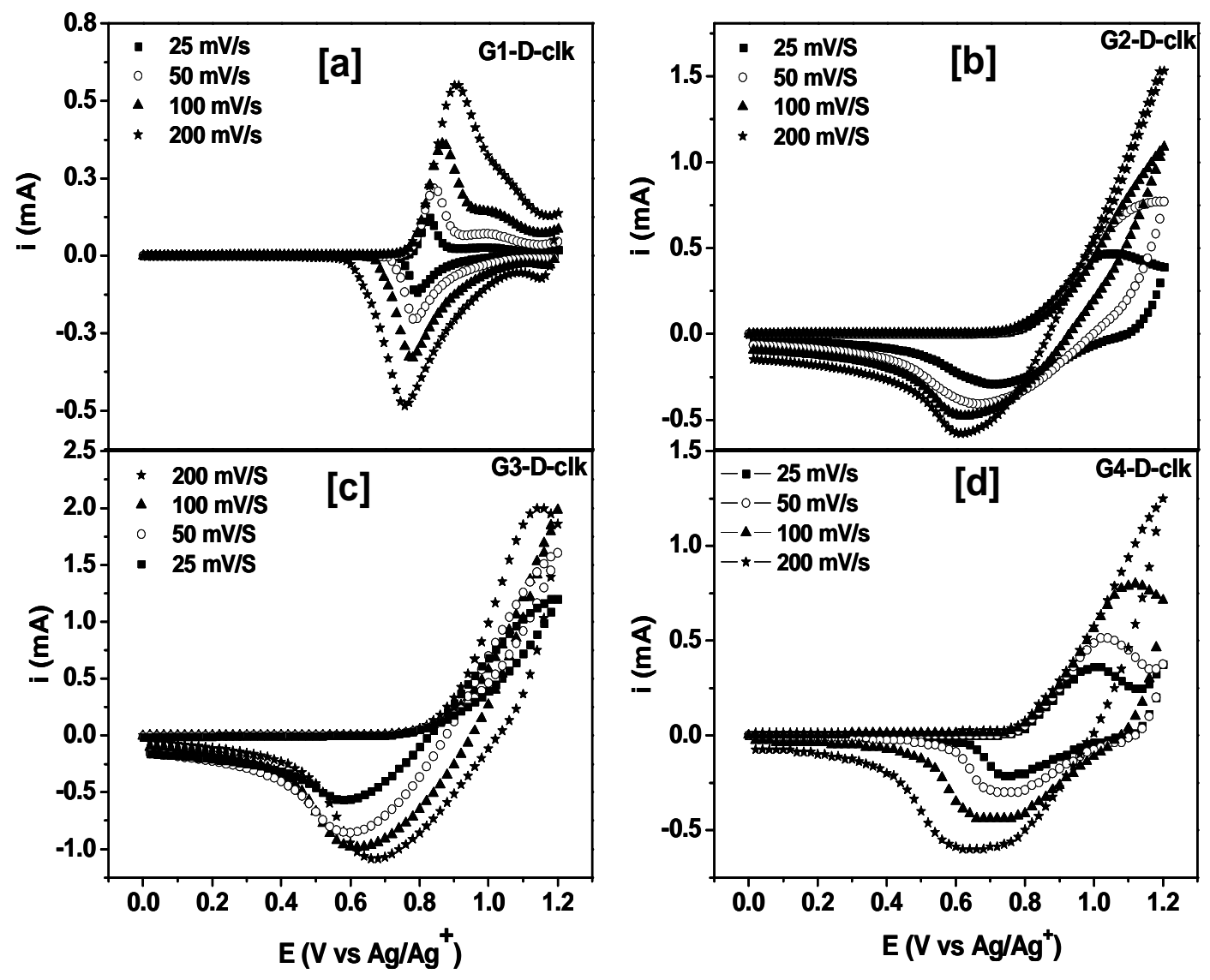

Figure 3. CV in monomer free conditions on the cross-linked film at a scan rate of 25 , 50,100 , and $200 \mathrm{mv} / \mathrm{s}$ in methylene chloride solution containing $0.1 \mathrm{mM}$ TBAP for dendrimers. 


\section{AFM Morphological studies.}
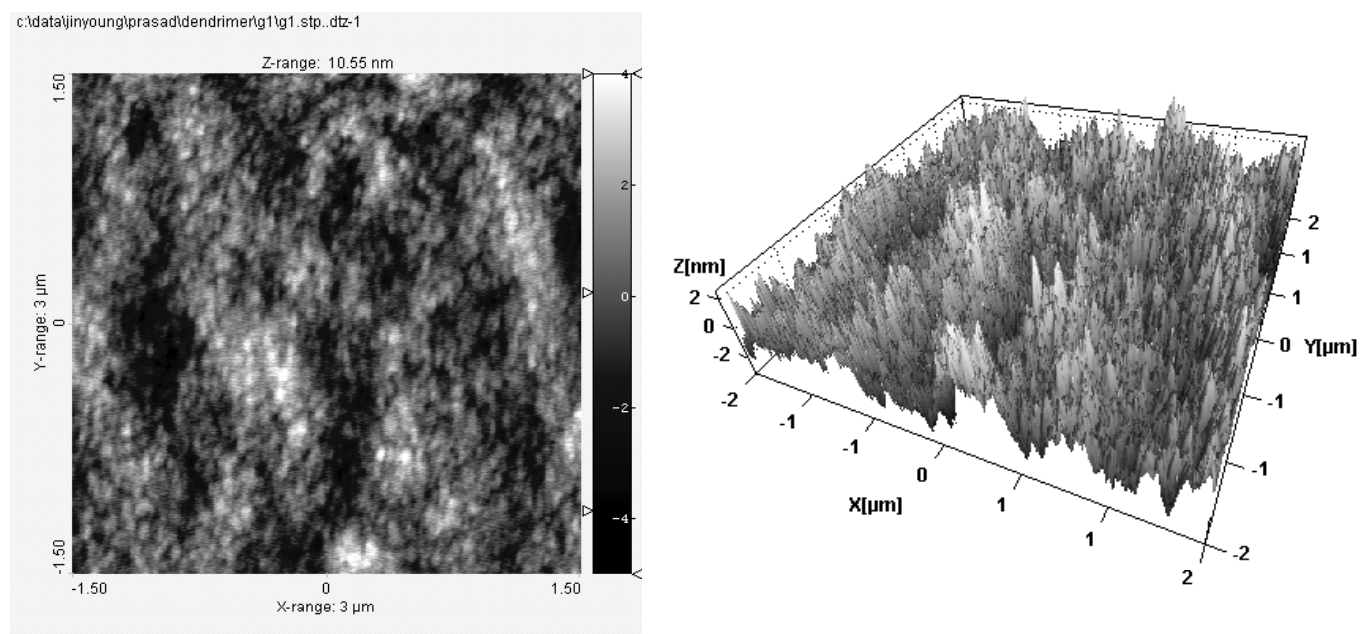

(a)
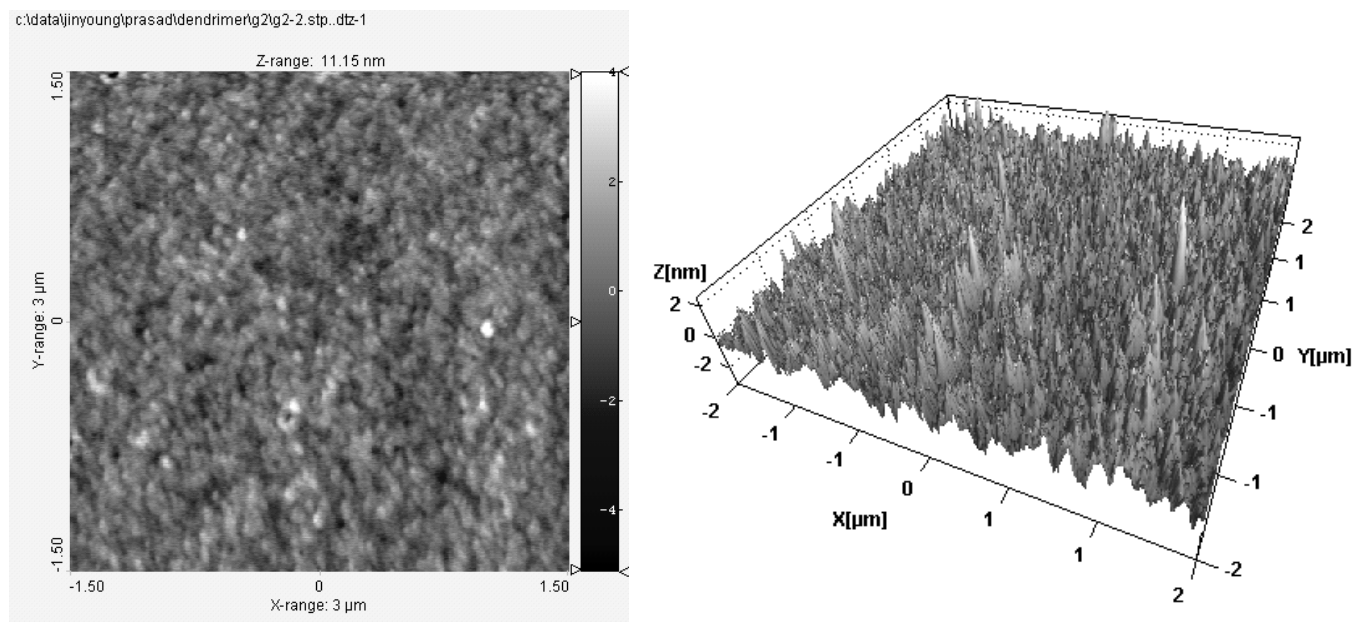

(b) 

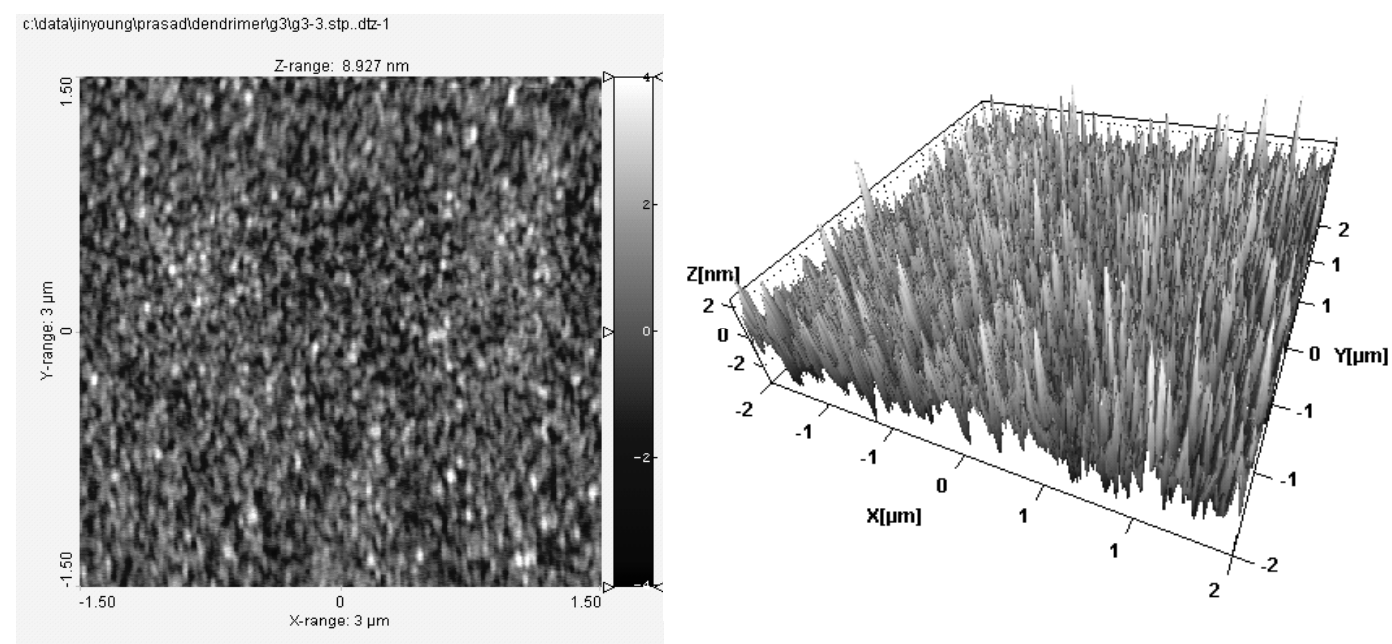

(c)
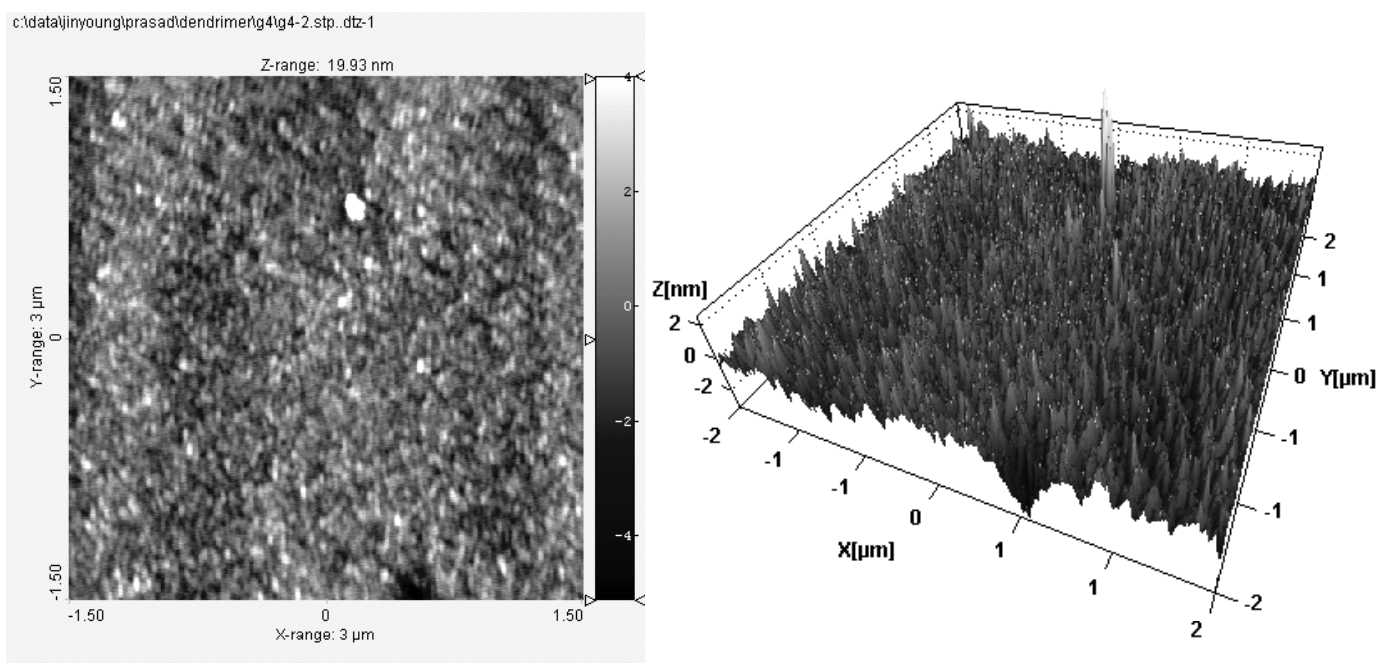

(d)

Figure 4. 2D/3D-AFM images of the cross-linked dendrimer films: (a) G1-D (b) G2-D

(c) G3-D (d) G4-D. 


\section{Cyclic Voltammetry studies for dendrimers and linear polymer PVK:}

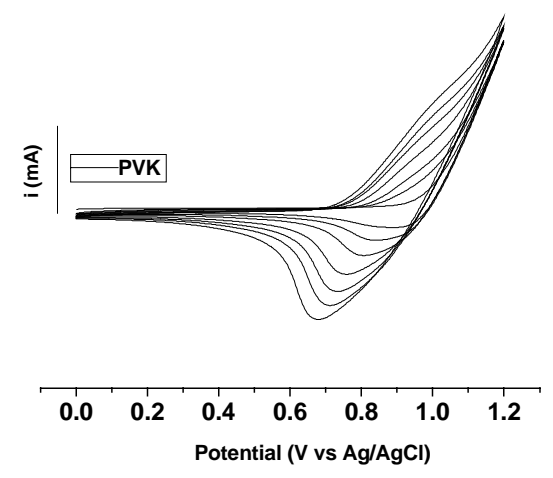

Figure 5. Cyclic voltamogram of PVK.

Electrochemical synthesis of cross-linked dendrimer precursors (G1-D-clk/

G4-D-clk/PVK). The precursor dendrimers were electro-polymerized using the cyclic voltammetry $(\mathrm{CV})$ technique. In a three electrode cell, $0.1 \mathrm{M}$ tetra butyl ammonium perchlorate (TBAP) was taken as a supporting electrolyte along with $1 \mathrm{mM}$ of each dendrimer dissolved in $4 \mathrm{ml}$ methylene chloride in separate cells. The electropolymerization of each precursor polymer was performed by sweeping the voltage at a scan rate of $20 \mathrm{mV} / \mathrm{s}$ from 0 to $1.2 \mathrm{~V}$ against $\mathrm{Ag} / \mathrm{AgCl}$ as a reference electrode and platinum as a counter electrode. The ITO or gold coated slides were used as a working electrode and also as a substrate. 


\section{Band Gap studies.}

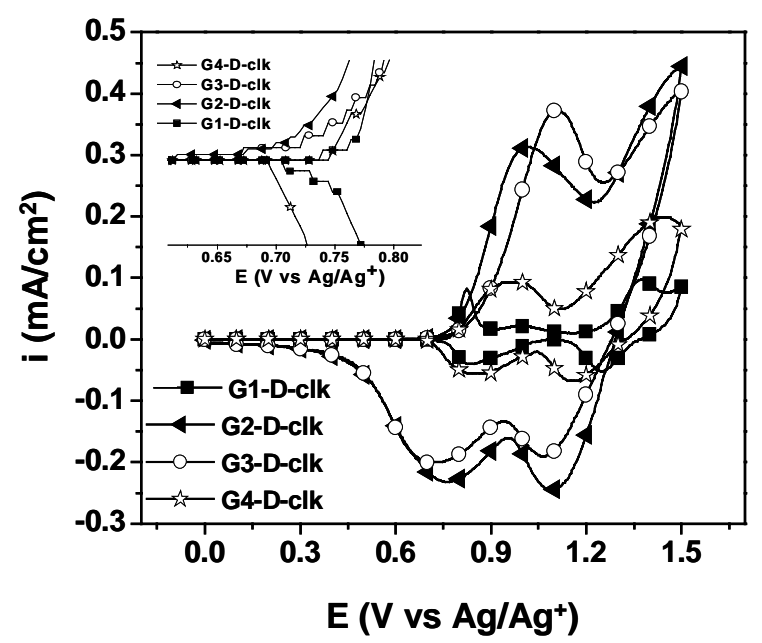

Figure 6. Anodic scan for cross-linked dendrimers in monomer free solution containing $0.1 \mathrm{mM}$ TBAP as a supporting electrolyte in methylene chloride and a saturated $\mathrm{Ag} / \mathrm{AgCl}$ reference electrode (having a potential of $0.2 \mathrm{~V}$ versus NHE). 


\section{${ }^{1} \mathrm{H}$ NMR for Dendrons and Dendrimers:}

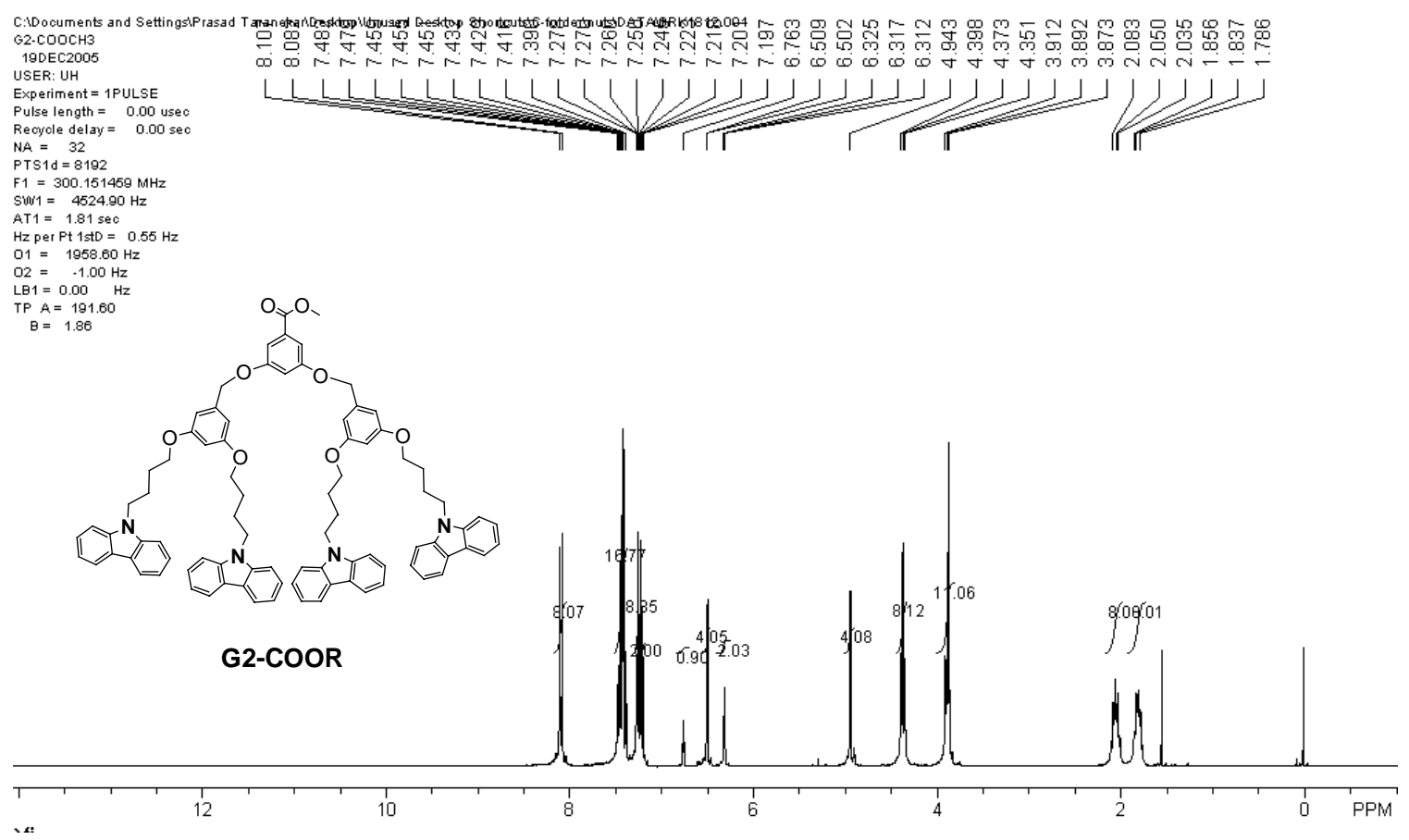

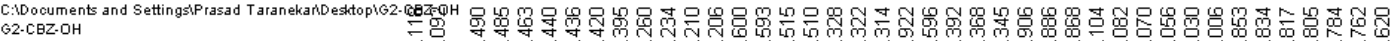

$158 E P 2005$

USER: UH

Experiment $=1$ PULSE

Pulse length $=0.00$ usec

Recyle delay $=0.00 \mathrm{zec}$

NA $=32$

$F 1=300.660461 \mathrm{MHz}$

$F 1=300.660461$
Silli $1=4524.90 \mathrm{~Hz}$

Silil' $1=4624.90 \mathrm{~Hz}$
$\mathrm{AT}=1.81$ seo

$\mathrm{Hz}$ per Ft $1 \mathrm{tat}=0.55 \mathrm{~Hz}$

$\mathrm{a}_{1}=1954.10 \mathrm{~Hz}$

$02=-1.00 \mathrm{~Hz}$

$\angle \mathrm{B} 1=0.00 \mathrm{HZ}$

$B=15.49$
$B=18$

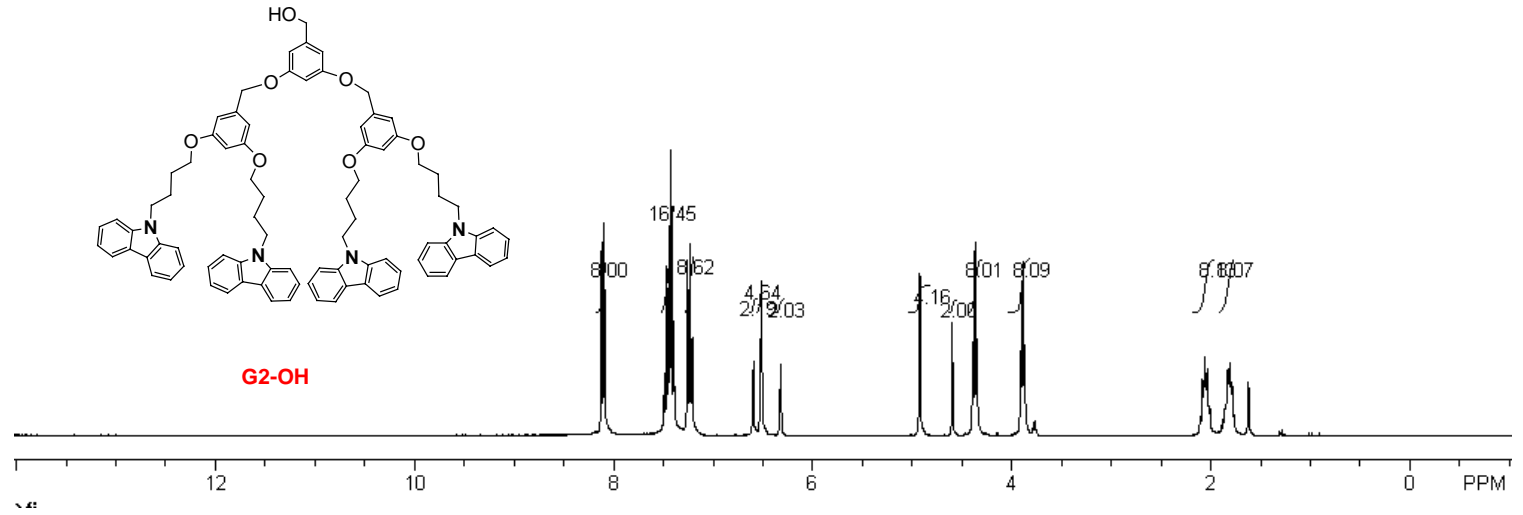



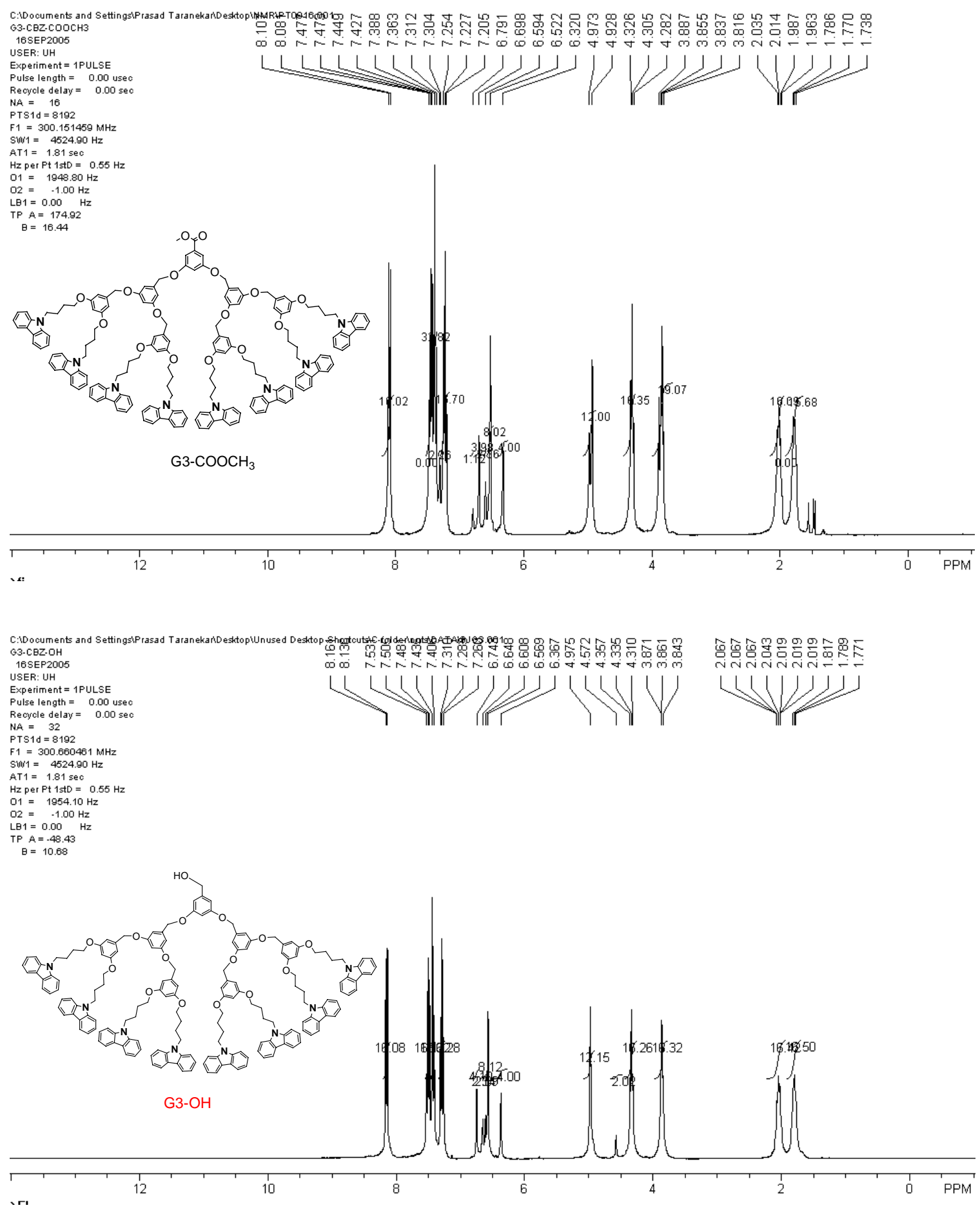


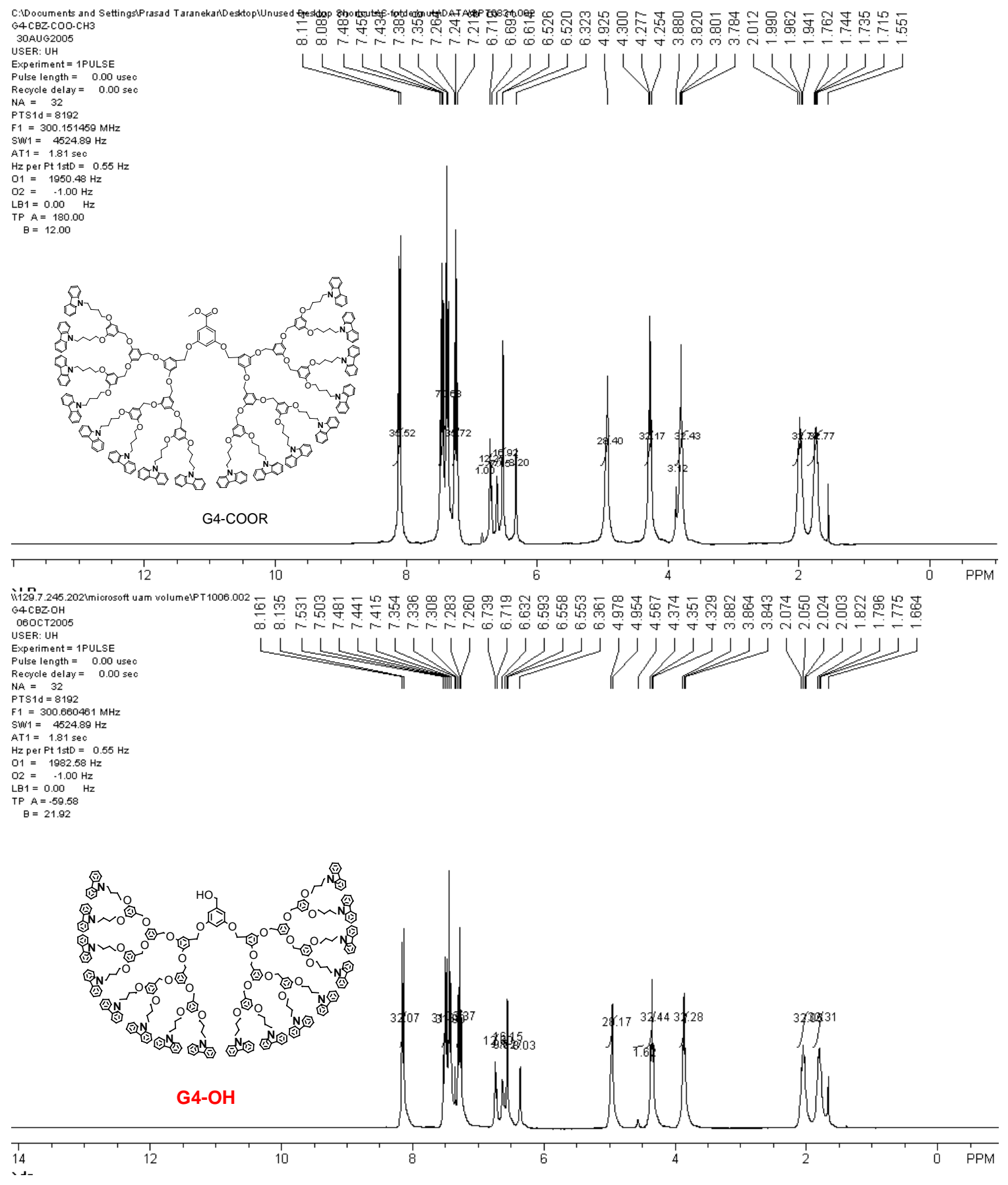




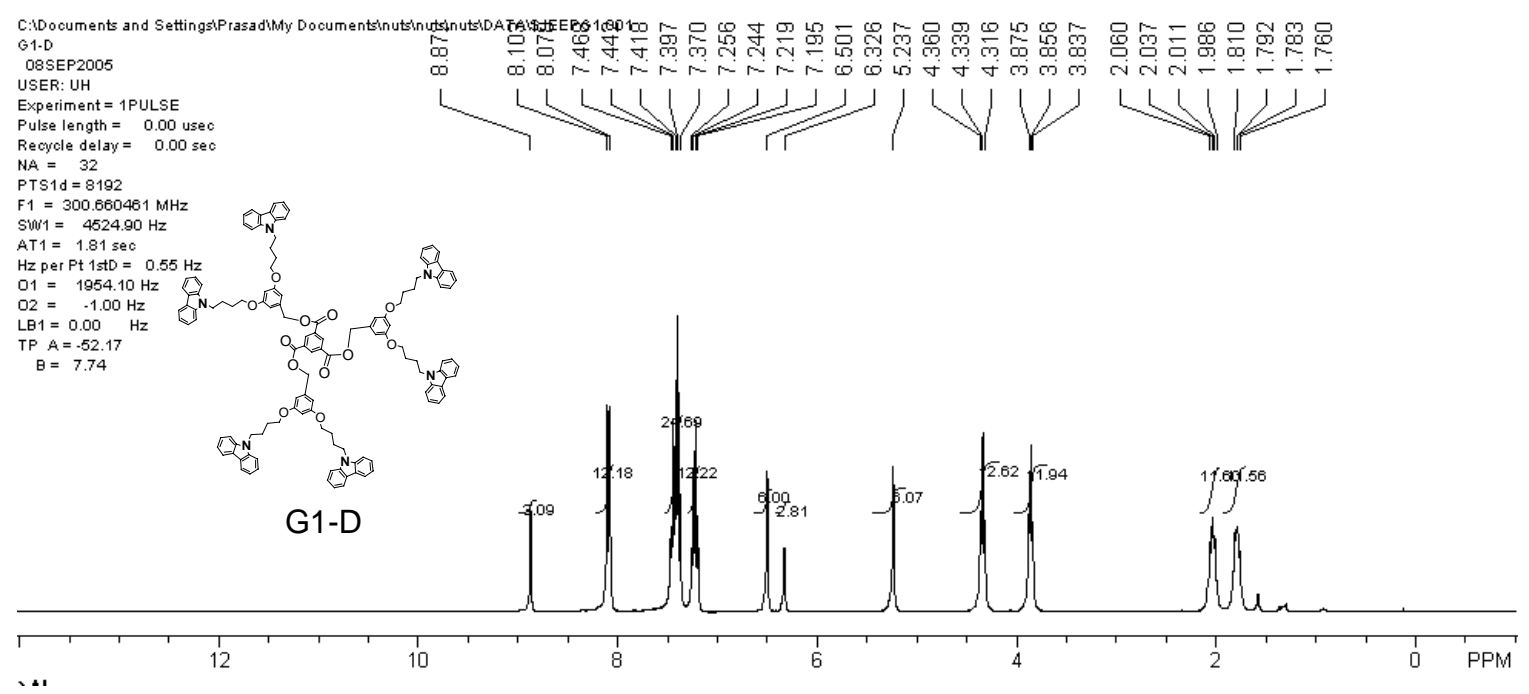

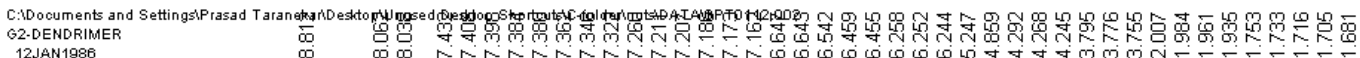

USER: UH

Experiment $=1$ PULSE

Pulse length $=0.00$ use

Recyole delay $=0.00$ sec

NAA $=32$

$P T S 1 \mathrm{~d}=8192$
$F 1=300.151459 \mathrm{MHz}$

Sili't $1=4524.09 \mathrm{~Hz}$

$\mathrm{Hz}$ per Ft $1 \mathrm{tat}=0.55 \mathrm{~Hz}$

ar $=1950.45 \mathrm{~Hz}$

$02=-1.00 \mathrm{~Hz}$

LEA1 $=0.000 \mathrm{HZ}$
$\mathrm{TPA}=187.91$

$\begin{aligned} & \mathrm{TP} A \mathrm{~A}=187.91 \\ & B=2.36\end{aligned}$

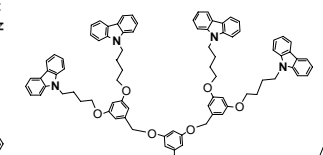

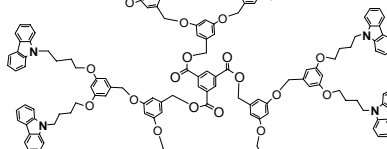

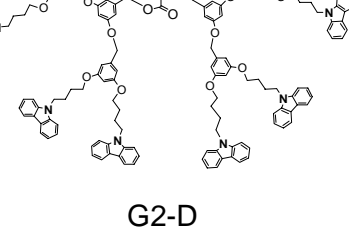
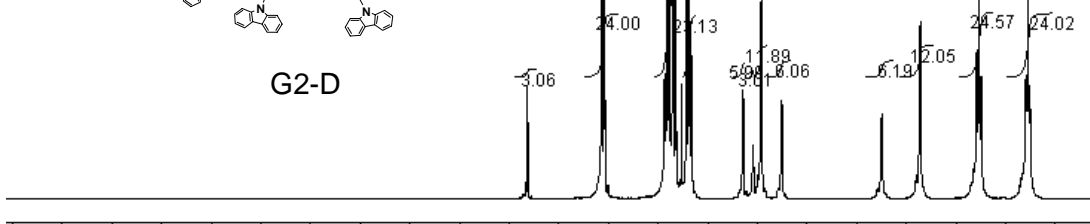

28.86 .69 

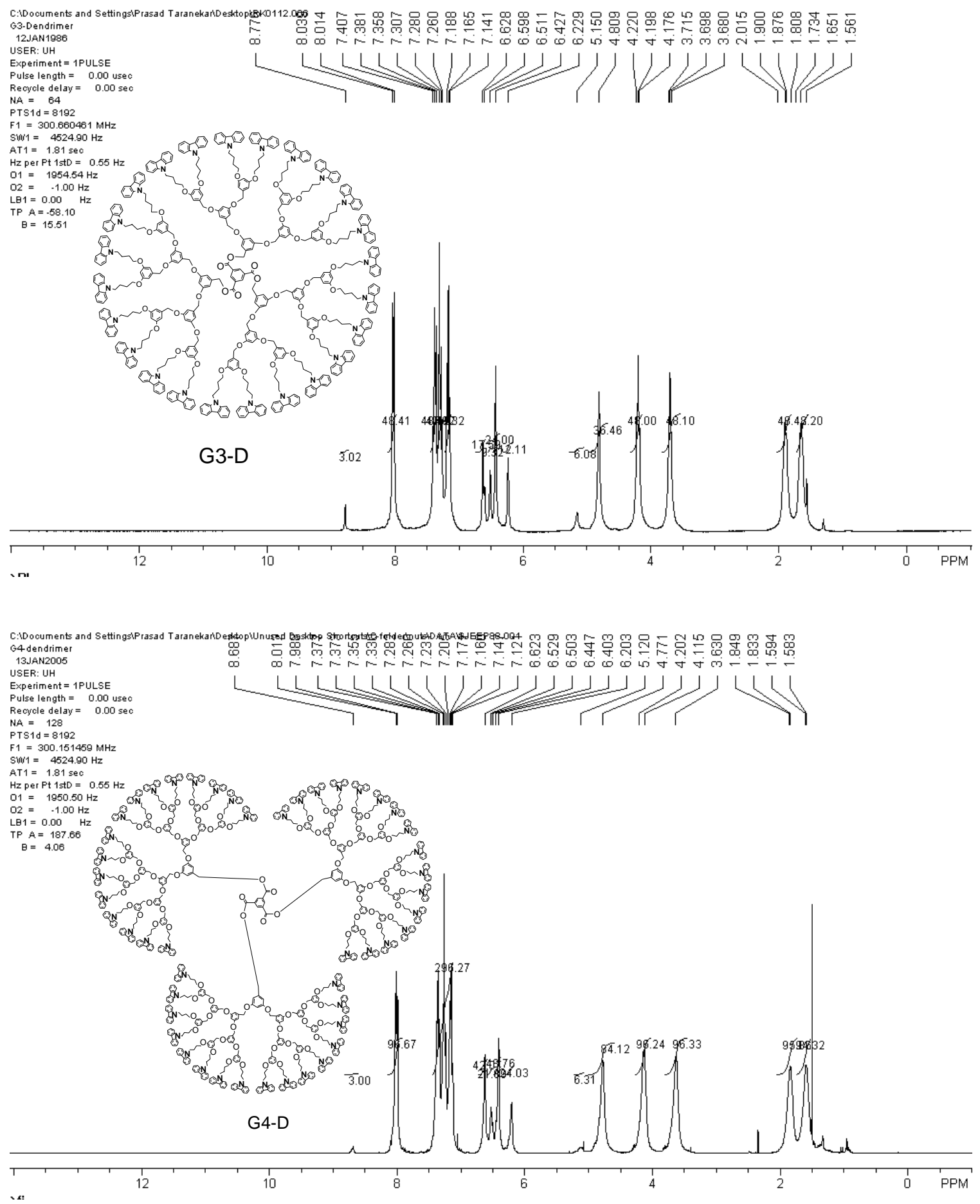